\title{
Stock Valuation: Dividend Discount Models
}

\author{
Syrgak Kydyraliev (American University of Central Asia, Kyrgyzstan) \\ Anarkul Urdaletova (Kyrgyzistan-Turkey Manas University, Kyrgyzstan)
}

\begin{abstract}
One of the most widespread problems on a securities market is the problem of definition of an estimated stock value. It is necessary to note, that the stock price as well as the price of any good in the market is defined as the result of supply and demand interaction. Our task is to offer the mechanism, which allows making decision on purchase or sale. For this purpose the method of asset estimation by future cash flows will be used - i.e. we believe that the estimated value of an asset is equal to present value of the future cash flows which are provided by the asset. In our paper we will introduce methods for the valuation of stocks with arithmetic and pseudoarithmetic growth of dividends.
\end{abstract}

JEL Code: G12

\section{Introduction}

The development of the real economy should be based on domestic investment. Therefore a chain of 3 elements should work: income, saving, and investment. The fact that this chain is not working in Kyrgyzstan makes us rely on foreign investors, while within the country hundred millions of dollars remain unused in the economy.

Many Kyrgyz economists consider the concentration of financial market in the banking sector as a problem. Private banks occupy more than $90 \%$ of the financial market, and only $10 \%$ is left for the market of securities. According to international data, the banking sector in the developed countries is not greater than $30 \%$ the financial market (Dobretsova, 2007).

As a result of lack of competition there is a big difference between interest rates on deposits and credits:

\begin{tabular}{|c|c|c|c|c|c|c|}
\hline & $\mathbf{2 0 0 3}$ & $\mathbf{2 0 0 4}$ & $\mathbf{2 0 0 5}$ & $\mathbf{2 0 0 6}$ & $\mathbf{2 0 0 7}$ & $\mathbf{2 0 0 8}$ \\
\hline Interest rate on credits, in \% & 26,06 & 24,56 & 25,41 & 25,59 & 28,7 & 30,1 \\
\hline Interest rate on deposits, in \% & 3,48 & 3,52 & 4,03 & 3,64 & 5,8 & 6,3 \\
\hline
\end{tabular}

Table 1: Interest rates on deposits and credits. Source: www.nbkr.kg

To overcome this disproportion it is necessary to develop the market for stocks and bonds. Therefore we should introduce the main concepts of this market to the potential market actors.

\section{Stable Dividends}

Stock valuation is an extremely challenging problem on the securities market. Supply and demand interaction determines the price of a stock as well as any other product. In order to make a proper decision to buy or sell the asset an investor needs to know its value.

For this purpose the presented paper uses the method of asset estimation by future cash flows, i.e. we consider the estimated value of an asset to be equal to the present value of the future cash flows provided by the asset. Future cash flows are dividends. They fluctuate according to different models through time.

For rough estimations it is enough to assume that the amount of dividends and the interest rate are stable (Ross, et. al, 1998). In this situation, assuming the unlimited number of dividends, the estimated stock value $(P)$, amount of dividend $(D)$, paid at the end of each period $(t)$, and cost of equity capital $(r)$ will be connected by a formula

$$
P=\frac{D}{1+k}+\frac{D}{(1+k)^{2}}+\frac{D}{(1+k)^{3}}+\ldots+\frac{D}{(1+k)^{n}}+\ldots . \quad k=r t
$$

Since the cost of equity capital is positive we deal with a decreasing geometric progression. Therefore, the stock value is defined by a formula:

$$
P=\frac{D}{k}, \quad k=r t
$$

\section{Constantly Growing Dividends}

The assumption that the amount of dividends is stable is too unrealistic. Therefore, a model in which dividends increase by the same percentage each period is offered - constant growth stocks valuation (Ross, et. al, 1998). 
In this situation the value of a stock $(P)$, amount of dividends $\left(D_{0}\right)$, paid before the stock valuation, a percentage growth of dividends $(g)$ and the interest rate $(r t=k)$ are connected by the following formula:

$$
\begin{aligned}
& P=\frac{D_{1}}{1+k}+\frac{D_{2}}{(1+k)^{2}}+\frac{D_{3}}{(1+k)^{3}}+\ldots+\frac{D_{n}}{(1+k)^{n}}+\ldots= \\
& \frac{D_{0}(1+g)}{1+k}+\frac{D_{0}(1+g)^{2}}{(1+k)^{2}}+\frac{D_{0}(1+g)^{3}}{(1+k)^{3}}+\ldots+\frac{D_{0}(1+g)^{n}}{(1+k)^{n}}+\ldots .
\end{aligned}
$$

When $g<k$ we have a decreasing geometric progression with ratio $\frac{1+g}{1+k}$. Therefore,

$$
P=\frac{D_{0}(1+g)}{k-g}
$$

In order to obtain (1) and (3) it is not necessary to use a formula for the sum of the decreasing geometric progression. It is sufficient to know, that the estimated stock value exists:

Let $P=\frac{D}{1+k}+\frac{D}{(1+k)^{2}}+\frac{D}{(1+k)^{3}}+\ldots+\frac{D}{(1+k)^{n}}+\ldots$.

Rewrite it as

$$
P=\frac{D}{1+k}+\frac{1}{1+k}\left[\frac{D}{1+k}+\frac{D}{(1+k)^{2}}+\frac{D}{(1+k)^{3}}+\ldots+\frac{D}{(1+k)^{n}}+\ldots\right]
$$

The expression within brackets is equal to $P$.

Therefore $P=\frac{D}{1+k}+\frac{1}{1+k} P$. Then, $\mathrm{P}(1+\mathrm{k})=\mathrm{D}+\mathrm{P}$ and $P=\frac{D}{k}$.

The same consideration allows us to get from

$$
P=\frac{D_{0}(1+g)}{1+k}+\frac{D_{0}(1+g)^{2}}{(1+k)^{2}}+\frac{D_{0}(1+g)^{3}}{(1+k)^{3}}+\ldots+\frac{D_{0}(1+g)^{n}}{(1+k)^{n}}+\ldots .
$$

formula (3). Rewrite (2) as

$$
P=\frac{D_{0}(1+g)}{1+k}+\frac{1+g}{1+k}\left[\frac{D_{0}(1+g)}{1+k}+\frac{D_{0}(1+g)^{2}}{(1+k)^{2}}+\ldots+\frac{D_{0}(1+g)^{n}}{(1+k)^{n}}+\ldots\right] \text {. }
$$

The expression within brackets is equal to $P$.

Therefore

$$
P=\frac{D_{0}(1+g)}{1+k}+\frac{1+g}{1+k} P \text {. }
$$

Then $P(1+k)=D_{0}(1+g)+(1+g) P$, and $P=\frac{D_{0}(1+g)}{k-g}$.

\section{Arithmetically Growing Dividends}

Now, we use the introduced method for the valuation of stocks with arithmetic growth of dividends.

Let $D_{0}$ be the amount of dividends paid recently. Assume that dividends at the end of each following period will be greater by some number $d$.

Valuing this stock by future cash flows, we get

$$
P=\frac{D_{0}+d}{1+k}+\frac{D_{0}+2 d}{(1+k)^{2}}+\frac{D_{0}+3 d}{(1+k)^{3}}+\ldots+\frac{D_{0}+n d}{(1+k)^{n}}+\ldots
$$

Rewrite (4) as $P=\frac{D_{0}+d}{1+k}+\frac{1}{1+k}\left[\frac{D_{0}+2 d}{1+k}+\frac{D_{0}+3 d}{(1+k)^{2}}+\ldots+\frac{D_{0}+n d}{(1+k)^{n-1}}+\ldots\right]$.

We split each ratio inside the brackets in two:

$[\ldots]=$ 
$=\left[\left(\frac{D_{0}+d}{1+k}+\frac{d}{1+k}\right)+\left(\frac{D_{0}+2 d}{(1+k)^{2}}+\frac{d}{(1+k)^{2}}\right)+\ldots+\left(\frac{D_{0}+(n-1) d}{(1+k)^{n-1}}+\frac{d}{(1+k)^{n-1}}\right)+\ldots\right]$.

The sum of the first terms equals $P$, and the sum of the second terms according to formula (1) equals $\frac{d}{k}$.

Therefore

$$
P=\frac{D_{0}+d}{1+k}+\frac{1}{1+k}\left[P+\frac{d}{k}\right]
$$

Then, $P(1+k)=D_{0}+d+P+\frac{d}{k}$, and $P k=D_{0}+d+\frac{d}{k}$.

As a result we obtain a formula for the valuation of stocks with arithmetic growth of dividends:

$$
P=\frac{D_{0}+d}{k}+\frac{d}{k^{2}} \text {. }
$$

\section{Pseudo-Arithmetically Growing Dividends}

We could ask: how realistic are these models?

Using other words: Are there any stocks with stable dividends; with arithmetic or geometric growth of dividends...?

Seems like there are no stocks with absolutely stable or geometrically growing dividends... At the same time you can find stocks which have stable dividends or approximately geometrically growing dividends during pretty long periods of time and so on.

Let's consider the data on Tiffany \& Co stocks.

\begin{tabular}{|c|c|c|c|c|c|c|c|c|c|c|c|}
\hline & $\mathbf{2 0 0 0}$ & $\mathbf{2 0 0 1}$ & $\mathbf{2 0 0 2}$ & $\mathbf{2 0 0 3}$ & $\mathbf{2 0 0 4}$ & $\mathbf{2 0 0 5}$ & $\mathbf{2 0 0 6}$ & $\mathbf{2 0 0 7}$ & $\mathbf{2 0 0 8}$ & $\mathbf{2 0 0 9}$ & $\mathbf{2 0 1 0}$ \\
\hline January & 0,03 & 0,04 & 0,04 & 0,04 & 0,05 & 0,06 & 0,08 & 0,1 & 0,15 & 0,17 & 0,17 \\
\hline April & 0,03 & 0,04 & 0,04 & 0,04 & 0,05 & 0,06 & 0,08 & 0,1 & 0,15 & 0,17 & 0,2 \\
\hline July & 0,04 & 0,04 & 0,04 & 0,05 & 0,06 & 0,08 & 0,1 & 0,12 & 0,17 & 0,17 & 0,25 \\
\hline October & 0,04 & 0,04 & 0,04 & 0,05 & 0,06 & 0,08 & 0,1 & 0,15 & 0,17 & 0,17 & 0,25 \\
\hline
\end{tabular}

Table 2: Dividends on Tiffany\&Co stocks. Source: www.tiffany.com

Dividends were paid 4 times a year, in one of the days, from $10^{\text {th }}$ to $12^{\text {th }}$, of the named months.

It can be noted, that quite long, from 2000 to 2003, dividends were stable.

We can observe even more interesting thing, if we remember, that the fiscal year in the U.S.A. starts in summer.

We rearrange the table and note two fragments:

\begin{tabular}{|c|c|c|c|c|c|c|c|c|}
\hline & $\mathbf{2 0 0 2 -}$ & $\mathbf{2 0 0 3 -}$ & $\mathbf{2 0 0 4 -}$ & & & $\begin{array}{c}\mathbf{2 0 0 4}- \\
\mathbf{2 0 0 3}\end{array}$ & $\mathbf{2 0 0 4}$ & $\mathbf{2 0 0 5}$ \\
& $\mathbf{2 0 0 5}$ & & $\begin{array}{c}\mathbf{2 0 0 5}- \\
\mathbf{2 0 0 6}\end{array}$ & $\begin{array}{c}\mathbf{2 0 0 6}- \\
\mathbf{2 0 0 7}\end{array}$ \\
\hline July & 0,04 & 0,05 & 0,06 & & July & 0,06 & 0,08 & 0,10 \\
\hline October & 0,04 & 0,05 & 0,06 & & October & 0,06 & 0,08 & 0,10 \\
\hline January & 0,04 & 0,05 & 0,06 & & January & 0,06 & 0,08 & 0,10 \\
\hline April & 0,04 & 0,05 & 0,06 & & April & 0,06 & 0,08 & 0,10 \\
\hline
\end{tabular}

Table 3: Dividends on Tiffany \& Co stocks throughout the fiscal year.

This observation allows us to generate a problem of the valuation of stocks with dividends stable within a fiscal year and growing by some number between years - the valuation of stocks with "pseudo-arithmetic" growth of dividends.

Suppose dividends $D_{0}$ are recently paid on a stock. At the end of each four following quarters they will be equal to $D_{1}=D_{0}+d$, then, in the next four quarters the amount of dividends will be $D_{2}=D_{1}+d=D_{0}+2 d$, and so on.

Then the estimated value of this stock will be:

$P=\frac{D_{1}}{1+k}+\frac{D_{1}}{(1+k)^{2}}+\frac{D_{1}}{(1+k)^{3}}+\frac{D_{1}}{(1+k)^{4}}+\frac{D_{1}+d}{(1+k)^{5}}+\ldots+\frac{D_{1}+d}{(1+k)^{8}}+\frac{D_{1}+2 d}{(1+k)^{9}}+\ldots$

Rewrite $\mathrm{P}$ as 


$$
\begin{aligned}
& P=\frac{D_{1}}{1+k}+\frac{D_{1}+d}{(1+k)^{5}}+\frac{D_{1}+2 d}{(1+k)^{9}}+\frac{D_{1}+3 d}{(1+k)^{13}}+\ldots \\
& +\frac{D_{1}}{(1+k)^{2}}+\frac{D_{1}+d}{(1+k)^{6}}+\frac{D_{1}+2 d}{(1+k)^{10}}+\frac{D_{1}+3 d}{(1+k)^{14}}+\ldots \\
& +\frac{D_{1}}{(1+k)^{3}}+\frac{D_{1}+d}{(1+k)^{7}}+\frac{D_{1}+2 d}{(1+k)^{11}}+\frac{D_{1}+3 d}{(1+k)^{15}}+\ldots \\
& +\frac{D_{1}}{(1+k)^{4}}+\frac{D_{1}+d}{(1+k)^{8}}+\frac{D_{1}+2 d}{(1+k)^{12}}+\frac{D_{1}+3 d}{(1+k)^{16}}+\ldots
\end{aligned}
$$

and introduce

$$
P_{4}=\frac{D_{1}}{(1+k)^{4}}+\frac{D_{1}+d}{(1+k)^{8}}+\frac{D_{1}+2 d}{(1+k)^{12}}+\frac{D_{1}+3 d}{(1+k)^{16}}+\ldots
$$

Then, $\mathrm{P}=(1+\mathrm{k})^{3} \mathrm{P}_{4}+(1+\mathrm{k})^{2} \mathrm{P}_{4}+(1+\mathrm{k}) \mathrm{P}_{4}+\mathrm{P}_{4}$.

Sum up the obtained geometric progression and obtain

$$
P=P_{4} \frac{(1+k)^{4}-1}{k} \text {. }
$$

Now transform $\mathrm{P}_{4}$ :

$$
\begin{aligned}
& P_{4}=\frac{D_{1}}{(1+k)^{4}}+\frac{1}{(1+k)^{4}}\left(\frac{D_{1}}{(1+k)^{4}}+\frac{d}{(1+k)^{4}}+\frac{D_{1}+d}{(1+k)^{8}}+\frac{d}{(1+k)^{8}}+\ldots\right)= \\
& =\frac{D_{1}}{(1+k)^{4}}+\frac{1}{(1+k)^{4}}\left(P_{4}+\frac{d}{(1+k)^{4}}+\frac{d}{(1+k)^{8}}+\frac{d}{(1+k)^{12}}+\ldots\right)= \\
& \frac{D_{1}}{(1+k)^{4}}+\frac{1}{(1+k)^{4}}\left(P_{4}+\frac{d}{(1+k)^{4}-1}\right) . \\
& \text { Then } \quad P_{4}\left[1-\frac{1}{(1+k)^{4}}\right]=\frac{1}{(1+k)^{4}}\left(D_{1}+\frac{d}{(1+k)^{4}-1}\right) \\
& \text { So } \quad P_{4}=\frac{D_{1}\left[(1+k)^{4}-1\right]+d}{\left[(1+k)^{4}-1\right]^{2}} .
\end{aligned}
$$

Replacing the expression for $P_{4}$ in formula (6), we get

$$
P=\frac{D_{1}\left[(1+k)^{4}-1\right]+d}{k\left[(1+k)^{4}-1\right]}=\frac{D_{1}}{k}+\frac{d}{k\left[(1+k)^{4}-1\right]} .
$$

Using this formula we have a possibility to evaluate stocks with "pseudo-arithmetic" growth of dividends.

\section{Conclusion}

Stock valuation can be a difficult task. In order to fulfill it various models can be used. In our paper we employed the method of asset estimation by future cash flows or dividends. We introduced the common models with stable and constantly growing dividends. Then we developed them to obtain new results, which can be applied for the assets on the real market.

This paper for the first time presents formulas for the valuation of stocks with dividends being members of an arithmetic progression and with dividends with pseudo-arithmetic growth. Such models make it possible to make investment decisions for different purposes.

We assume this paper to be useful for specialists working on stock market. Moreover, the content of the current paper can be a part of the variety of classes, such as Corporate Finance, Investments, etc.

\section{References}

- Dobretsova N.N., 2007. Romantic of Capital. CENTI, Bishkek, p. 112-121

- Ross, Westerfild and Jordan, 1998. Fundamentals of Corporate Finance. IRWIN, Chicago, p. 188-200 